\title{
An Alternative Model of Continuing Professional Development for \\ Teachers: Giving Teachers Time
}

\author{
Terry Haydn \\ School of Education and Lifelong Learning, University of East Anglia \\ Norwich, NR4 7TJ, England \\ Tel: $00441603593150 \quad$ E-mail: t.haydn@uea.ac.uk \\ Roy Barton \\ School of Education and Lifelong Learning, University of East Anglia \\ Norwich, NR4 7TJ, England \\ Tel: 00441603593155 E-mail: r.barton@uea.ac.uk \\ Ann Oliver \\ School of Education and Lifelong Learning, University of East Anglia \\ Norwich, NR4 7TJ, England \\ Tel: 00441603592627 E-mail: a.e.oliver@uea.ac.uk
}

The research was financed by the Department of Culture, Museums and Sport, UK.

\begin{abstract}
The paper reports on the outcomes of a Department of Culture, Museums and Sport (DCMS) funded project which provided resources for three groups of teachers in different subjects and age phases to have some time where they were freed from their teaching responsibilities, and also given time to meet together with other teachers to share ideas. The idea underpinning the project was to explore a model of continuing professional development for teachers which was different in approach to recent Department for Education and Skills (DfES) 'strategy' and training based approaches.
\end{abstract}

The three groups of teachers (primary science, secondary history and secondary science) met together with curriculum tutors from the local School of Education to explore ideas about how to develop innovative approaches in aspects of their subject teaching. In addition to funding four days of supply cover for the teachers involved to meet, the teachers were also given at least two days of supply cover during the course of the project to develop their ideas. Towards the end of both academic years, the groups met again to share their ideas.

The paper describes the outcomes of the project and the teachers' perceptions of the process issues and problems involved in pedagogical innovation. The paper also considers some of the broader issues arising from the project, in terms of how to make the most effective use of teachers' time, in an era when there are many competing demands on this finite resource.

Keywords: Education, New technology, Teacher education, In-service training, Continuing professional development

\section{Background to the project}

The past few years have seen a resurgence of interest in the idea of 'teacher-centred' professional development in the United Kingdom, with initiatives such as the Networked Learning Communities initiative (NCSL, 2004), the 'Best Practice Research Scholarships' sponsored by the Department for Education and Skills (DfES), and the idea that teachers across schools will work collaboratively to improve teaching and learning outcomes (DfES, 2005a). However, in terms of overall investment in continuing professional development for teachers in England, the emphasis has been on centrally directed programmes and 'strategies' which are 'rolled out' and 'delivered' across the system as a whole (see, for instance, DfES, 2005b, DfES, 2005c).

\subsection{The teachers involved in the project}

Many of the teachers and lecturers in our initial teacher education partnership had expressed concern about the increasing prescription of DfES initiatives in recent years, with the proliferation of strategy documents and the possible 
atrophy of teacher initiative, originality and imagination in approaches to subject pedagogy and the erosion of subject specific Continuing Professional Development (CPD) courses. A generation of teachers has grown up unaware of the previous existence of Teachers' Centres where teachers from local communities of schools used to meet up, both to socialise and to discuss educational issues.

\subsection{Funding for the project}

Funding from the Department of Culture, Museums and Sport (DCMS) as part of its 'Creative Partnerships' initiative enabled us to undertake a two year action research project which aimed to give teachers in particular subject areas time to develop their own ideas for enhancing teaching and learning and time to meet up to share their ideas and initiatives. The underpinning hypothesis behind the project was that recent government initiatives in education in England have added to teachers' overall workload (see, for example Smithers and Robinson, 2000, NFER, 2000, Cockburn and Haydn, 2004) and resulted in a lack of time and opportunity for teachers to develop their own ideas and talk about teaching and learning issues with fellow professionals.

\subsection{The aims of the project}

The overarching aims of the project were to use the funding to provide time for teachers to develop their ideas for innovative pedagogy in subject teaching, to be able to 'try things out' in areas of their subject which were of interest to them, and to provide time for them to meet together to discuss and share their ideas with other teachers.

\subsection{Teacher response to the project}

The first year of the project involved over 40 teachers and almost all the teachers who were involved in the first year of the project wanted to be involved in the subsequent work when Phase Two funding was secured. Overall, numbers had to be limited because of funding constraints. The response led us to feel that we were to at least some extent 'knocking on an open door' in terms of teachers' desire to have time to pursue their own learning agendas and talk about these with colleagues from other schools.

\section{The three stands of the project}

We were aware from our work with teachers in our initial teacher education partnership that many regretted the paucity of subject specific CPD courses in the wake of the recent priority given to government directed national strategy programmes, which have an emphasis on generic teaching skills rather than subject specific dimensions of pedagogy. The three stands of the project reflected the subject areas of the university tutors involved; primary and secondary science, and secondary history. The pattern of activity was the same for all three strands; a one day research workshop to explain the project, share ideas and identify areas of interest, the funding of a day of supply cover so that teachers got some time to follow up and develop their interests, and an end of year follow up workshop, to share ideas and reflect on the experience of this form of CPD.

\subsection{Project ethos}

In all three cases, it was deemed important that teachers should be free to pursue whatever aspects of subject pedagogy interested them. There was no attempt to 'sub-contract' areas of work in order to achieve 'coverage' of the subject domain, and there was a deliberate attempt to avoid any audit or target setting procedures. In many respects, this goes 'against the grain', in terms of current emphasis in the UK education system (and elsewhere) on teacher accountability, audit and target setting (Ball, 2004, Elliott, 2001). Teachers were encouraged to come to the second workshop whether or not they had come up with a substantial 'outcome' from their involvement in the project. The final part of the day in the end of year workshops was devoted to evaluation of the experience of involvement in 'teacher-centred' CPD.

\subsection{Project activities}

The three stands spawned a range of activities. In secondary science, these included work on pupil misconceptions at Key Stage 3, 'Bringing applied science to life', running Science clubs outside taught time, the development of online testing for Triple Science GCSE and developing skills in scientific investigation. Many of the participants were at the 'cutting edge' in their particular field of interest and one participant described the final workshop as ' $a$ series of masterclasses in science teaching'. In addition to presenting their work, in several cases, the teachers involved had made their work available on the internet so that others could access it.

The secondary history strand of the project focused primarily on developing the use of ICT in subject teaching, a major concern for many heads of department in the partnership. Teachers worked on a range of projects, sometimes within their own department, sometimes pairing up with colleagues with similar interests. Areas of work included 'How to make PowerPoint less boring', the use of digitized 'impact' moving image resources, the development of departmental and revision websites, and building up 'collections' of visual resources on particular historical topics.

At the end of year meeting, 13 teachers attended the session, with two others sending their apologies for absence. Twelve of those attending the session had some form of 'product' which had stemmed from their involvement in the 
project, and some form of story to tell about how the product had been developed and how the department had progressed in ICT over the course of the year.

In the second year of the project, activities included work on using digital video editing with internet archive resources, advanced elements of Macromedia Flash, exploring the potential of interactive whiteboards and using Microsoft Photostory for storyboarding in history.

Participants ranged widely in their degree of prior expertise in ICT, with some at the 'cutting edge' of developments in ICT and others acknowledging that they were less assured in their technical expertise. This did not seem problematic, and there seemed to be some advantages to having a 'mixed ability' group, given the overall collegial 'climate' of the workshop. Those who had developed resources and activities in the course of the project were happy to share these on CD-roms.

The primary science strand of the project involved 18 teachers. Numbers were limited because of funding constraints, and several other schools expressed an interest should places become available. Research interests and activities included pupil participation in a science club, questioning, replacing activities to teach the QCA scheme of work, using models to enhance understanding, using thinking skills to develop science knowledge, linking DT and science, 'not setting targets', 'giving pupils ownership', teaching science through challenge and science through play.

\subsection{End of project teacher responses}

As with the secondary history and secondary science strands of the project, the end of year workshops evinced positive comments and feelings from those involved. Teachers talked about their individual projects with enthusiasm. It was generally felt that the projects had inspired a freer and more creative approach to teaching science. Many commented on a positive attitude and higher level of engagement from pupils. One teacher especially felt that her teaching had changed considerably and so had her feeling about science. She felt less constrained by plans and more driven by the children's questions. Through the project she realised that her teaching style had become more creative and she was more enthusiastic about science. As a result she ran a session for teachers in her school:

'I can't believe the difference it has made to my teaching. Now I let the children take the lead, follow the questions they ask and it all happens, it really does. They are just so keen, they ask me when are we doing science. They just love it and there are always bits of experiments going on, not just in the lesson.'

None of teachers felt that the action research which they had undertaken had had a detrimental effect or that it was a waste of time. They were all keen to talk about their projects with the group. It was noticeable that they were impressed by each others' explanations and several thought that they would try out some of the ideas presented. In the end of year workshop, feedback on involvement in the project was very positive; one teacher remarked that 'it is just amazing that we have all tried such different things, there is so much here. It's so diverse but so much we could take from every project' and there was a general murmur of assent to this.

\section{Teachers' reflections on the project}

Evaluation of the project was conducted partly through discussion groups in the concluding sessions of the research workshops, and partly through e mails and subsequent phone or face to face conversations with participants.

In all, over 60 teachers were involved in the three projects, spread across over 30 different schools. There is ample evidence from the project outcomes that many of the teachers involved invested many hours of work in the project, above and beyond the days of supply cover which was funded by the project.

\subsection{Outcomes and process issues}

The project was not uniformly successful; not all the teachers involved made progress with their declared area of interest, and good intentions had not always translated into action. At the end of year research workshops, there were a few teachers who acknowledged that they had not completed the work that they had intended to. One of them reported 'I'm afraid I don't have a great deal to offer. We were supposed to work on updating the revision website but as with many great intentions it didn't end up happening.' However, over $85 \%$ of the participants felt that they had accomplished something worthwhile from involvement in the project, and in some cases, reported that the work had a transformational effect on their practice. Sometimes this was in the form of a particular resource, such as a departmental website, in other cases it was a radical change in the use of new technology, the ways in which planning for learning was organised, or the degree of autonomy and responsibility accorded to pupils.

Initially it was envisaged that participants would stay in close touch by e mail and phone over the course of the year to keep up to date, share ideas and map developments, but beyond a handful of phone calls and e mails this didn't happen. The business of school life interceded and 'chats' to talk about how things were progressing clearly fell into the category of 'luxury items'. 
Also, although funding was available to provide supply cover which would give teachers time to develop their ideas, in some cases, the exigencies of examination classes or the overall cover situation within schools prevented teachers from making use of the funding which was available.

But in spite of these caveats, it was clear that the participants involved had enjoyed being involved in the project and considered it worthwhile, in spite of the many other demands on their time. In the words some teachers 'confessed' to not getting as far as they had hoped with their research but still felt that there had been some positive aspects to having been involved in the project:

'The day gave you time to think and it was very enjoyable... there was a nice atmosphere.. I like the combination of having some time with other teachers to just share ideas - and frustrations.'

The end of term was taken up with the organization of the Battlefields trip. We were hoping to spend time on it towards the end of term but I'm not sure. I would love to have the opportunity to try and do something like this at my new school so if anything ever comes up let me know.'

'We've not followed up things as much as we hoped but I am meeting up with J. (from another school involved in the project), using one of the supply days.... I It was helpful and I'm glad I got involved.'

Apart from gains in terms of 'outcomes' and products there were important 'process' issues involved in participation. Teachers welcomed the opportunity to talk about pedagogy with their peers, they enjoyed having time to reflect and explore ideas and recent developments which have the potential to influence the ways in which they teach their subject, and they enjoyed the chance to be creative in their approaches to subject pedagogy. This was apparent from the end of session discussions (teachers valued both the chance to meet up together and to have time to develop their ideas further within their own departments), and from the fact that nearly all of the teachers involved in phase 1 of the project had wanted to be involved in phase 2 .

The end of workshop discussions included (unsolicited) comments about other recent experiences of CPD, and in particular, unfavourable comparisons were made with participants' experiences of New Opportunities Fund (NOF) training in the use of ICT. (This was a compulsory and highly directive training programme for practising teachers to address a perceived deficit in qualified teachers' ICT proficiency: see Leask, 2002 and Ofsted, 2002 for external evaluations of the programme). Almost without exception, experiences of this training programme were described in very negative terms. A selection of comments which is not unrepresentative is given below:

'A waste of money.. and created a lot of resentment.'

'It was like a driving lesson that consisted only of learning the highway code but which had not actual driving tuition.'

'The training provided was patronising, unrealistic and painful in its delivery... The effect on staff morale was devastating. Nothing in recent years has done more to put teachers off using ICT.'

'I was tasked to deliver the training and implemented one course with 15 members of staff.... attendance dwindled within weeks to four or five and the course was never fully completed. I was unable to coax any other staff onto the course as they had heard of the experiences of others.'

'It was "done to us" in a way that left us deflated and angry. We needed time to debate and trial ideas - we did not have this. The sessions were geared around certain information which was going to be delivered come what may and usually this was not really linked to what we wanted to do. We persevered despite the training, not because of it.'

Although not all the teachers involved in the project had made drastic or transformational progress in their declared area of interest, none of them suggested that involvement had been 'harmful' or a waste of time. Feedback suggested that a key element of the positive views expressed was the degree of autonomy accorded to participants, and the absence of 'target setting' and 'audit' activities and climate. This relates to Woods' (1990) principles of 'relevance, ownership and control'; at least they had been free to explore aspects of teaching and learning that they were interested in and had chosen to pursue. In many cases, the teachers involved felt that they had achieved their objectives and had managed to improve aspects of teaching or learning in their schools. Some had clearly invested much more time in their research than that provided for by the funding of the project. The idea of simply giving teachers free time, with a fairly general brief to explore an area of interest goes 'against the grain' in these audit-heavy and target driven times, but it seemed to us that teachers were so thrilled to get even these modest amounts of time that they regarded it as a wonderful luxury that should not be abused.

\section{Implications for investment in post qualification development for teachers}

In the end of year workshops, teachers in all three groups felt that the combination of being given some time to work within their own departments in school, and some time to 'bounce ideas off each other', and demonstrate their work in progress and receive feedback on it from others, had been more helpful than having one or the other option. Fullan (1982, p. 259) has argued that 'teaching suffers from the lack of opportunity that teachers have as individuals, and 
particularly in interaction with other teachers, to reflect, to observe, to discuss, to plan.' This was borne out by the feedback from the end of project comments of the teachers involved. As one teacher remarked:

'We did feel inspired and energised after talking with everyone during the first meeting, it was the stimulus of this contact and interaction that started us going, and got us beyond the 'good intentions' stage. Sharing the outcomes and meeting up again was also really enjoyable and interesting, and has set us off on new tracks.'

There were several comments of this nature, and even the teachers who admitted that they had not brought their good intentions to fruition reported that they were still glad that they had got involved and felt that they had still 'got something out of it'. Teachers who had successfully developed some facet of their teaching showed no apparent rancour or unwillingness to share their work with those who had not 'brought something to the table'.

In all three strands of the project, teachers felt that 'lack of time' was a key deterrent to developing subject pedagogy. Many of those involved felt that without the day of cover and two days to meet and talk, their personal project would not have got off the ground. In 1975, Stenhouse argued that 'the most serious impediment to the development of teachers as researchers - and indeed as artists in teaching - is quite simply shortage of time.' (Stenhouse, 1975: 111). From the comments emanating from the end of workshop discussions, it was clear that teachers felt that the balance of 'time to do what you yourself would like to do professionally', and 'time during which you are directed what to do professionally' had shifted in a way which created resentment and which was not seen as helpful or effective.

This is not to argue against any form of centralised national strategy type forms of CPD for teachers, but to suggest that teacher-led, 'bottom-up' forms of CPD may well constitute a useful complement to standardised 'rolled out' forms of $\mathrm{CPD}$, and that the balance between the two forms of CPD may not be optimal at the present moment in the UK. Desforges (2004: p. 2) has argued that in terms of 'significant return', decentralised teacher led research may well be a more powerful driver of educational improvement than government programmes.

Many teacher training programmes, both for pre-service and qualified teachers have tended to go for a 'coverage' model. In 1998, Anthea Millett, Chief Executive of the Teacher Training Agency argued that by spelling out more comprehensively than ever before the competences which trainee teachers would be obliged to possess before being licensed to teach, these new 'improved' Standards for the award of Qualified Teacher Status would ensure that the breadth of newly qualified teachers' competence would be higher than ever before (Millett, 1998). The New Opportunities Fund Programme for developing teachers' ability to use ICT in subject teaching was another example of 'coverage' mentality - teachers were to be 'trained' to use a wide variety of ICT applications so as to become 'completely equipped' in ICT.

The experience of this project suggests that there may be some advantages in letting teachers have at least some say in determining their own learning agendas for their CPD, and that allowing them to pursue particular areas of interest and enthusiasm may be more beneficial than attempting 'across the board' training, which may be broader but more shallow in effect. Although this may result in some 'black holes' in their areas of expertise, there would appear to be significant advantages in terms of their motivation, engagement and sense of professionalism. The cost of the project was not inconsequential (approximately $£ 7,000$ per year for each strand), but the costs of other forms of investment, such as the NOF training programme, and DfES directed 'strategies' are substantial. It is possible that simply providing teachers with time to think, and to talk to each other, is a comparatively cost-effective form of continuing professional development.

\section{References}

Cockburn, A. and Haydn, T. (2004). Recruiting and retaining teachers: understanding why teachers teach. London: RoutledgeFalmer.

Department for Education and Skills. (2005a). White Paper: Higher standards, better schools for all. London: DfES.

Department for Education and Skills. (2005b). Secondary National Strategy for school improvement: pedagogy and practice, teaching and learning in secondary schools. London: DfES.

Department for Education and Skills (2005c). Secondary National Strategy for school improvement: leading and coordinating CPD in secondary schools. London: DfES.

Desforges, C. (2004). On learning and teaching. Cranfield: NCSL.

Elliott, J. (2001). Characteristics of performative cultures: their central paradoxes and limitations as resources for educational reform. In D. Gleeson and C. Husbands (Eds.) The Performing School, (pp. 192-209). RoutledgeFarmer: London and New York.

Fullan, M. (1982). The meaning of educational change. Ontario: OISE Press.

Leask, M. (2002). Training for teachers and librarians in the use of ICT, London, TTA.

Millett, A. (1998). Times Educational Supplement, 22 May. 
National Foundation for Educational Research (NFER). (2000). Who would be a teacher? A review of the factors motivating and demotivating prospective and practising teachers. Slough: NFER.

National College of School Leadership. (2004). Networked Learning Communities: learning about learning networks. Cranfield, NCSL.

Ofsted (Office for Standards in Education) (2002). ICT in schools: the effect of government initiatives, progress report, April 2002, London, Ofsted.

S.J. Ball. (2004). Constructing accountability: networking governance and management agency. Public Policy and Administration, 19, 17-33.

Smithers, A. and Robinson, P. (2000). Attracting teachers: past patterns, present policies, future prospects. Liverpool: Carmichael.

Stenhouse, L. (1975). An introduction to curriculum research and development. London: Heinemann.

Woods, P. (1990) Teacher skills and strategies. London: Falmer. 